\title{
EL MESTIZAJE EN MANUALES ESCOLARES DE GEOGRAFÍA DE COLOMBIA (1975-1990)
}

\section{The racial mixing in the Colombian textbooks of geography (1975-1990)}

\author{
Carmen Patricia Cerón Rengifo \\ Departamento de Ciencias Sociales. Universidad de Nariño (Colombia) \\ Correo-e: patriciac@udenar.edu.co \\ Recepción: I9 de diciembre de 2014 \\ Envío a informantes: 17 de enero de 2015 \\ Aceptación definitiva: 27 de febrero de 2015 \\ Biblid. [0214-3402 (2015) (II época) n. ${ }^{\circ}$ 2I; 22I-232]
}

REsUmen: El mestizaje como contenido de enseñanza en los manuales escolares de geografía de Colombia, publicados entre 1975 y 1990, hace parte de la clasificación social producida en las relaciones sociales racistas. Como tal, la población se acota en categorías jerarquizadas nombradas como mestizo/mulato/zambo y grupo triétnico, bajo el criterio de cruzamiento entre razas. Se enmarca en la autocomprensión de las élites, de la representación de sí mismas y de los demás, bajo la mirada del racismo.

Palabras clave: mestizaje; manuales escolares; geografía; educación secundaria; mestizos; mulatos; zambos.

Aвstract: Miscegenation and content of instruction in geography textbooks Colombia, published between 1975 and 1990 , is part of social classification produced in racist social relations. As such, the city is bounded on hierarchical categories named as mestizo / mulatto / Sambo and three races group, under the criterion of crossbreeding. It is part of the self-understanding of the elites, the representation of themselves and others, under the gaze of racism.

KEY WORDs: crossbreeding; textbooks; geography; secondary education; mestizos; mulattos; baboons.

\section{INTRODUCCIÓN}

$\mathrm{U}$ N RECURRENTE CAMINO DE INVESTIGACIÓN HA CONSTATADO que los manuales escolares son portadores, de manera explícita o implícita, de la ideología del colectivo social del que proceden (Choppin, 200o). Siguiendo este presupuesto, y entendiendo la ideología como el conjunto de creencias compartidas que fundamentan 
las representaciones sociales de un grupo social y que hacen parte de las relaciones de poder, dominio y conflicto entre los grupos (Van Dijk, 2008), exploramos las categorías de identificación de la población asociada al mestizaje, las cuales son utilizadas en los contenidos de enseñanza en una muestra de ocho manuales escolares de geografía de Colombia, destinados a estudiantes de sexto grado de secundaria, publicados entre 1975 y 1990, momento previo a la Constitución de I99i, en la que se declara que el Estado reconoce y protege la diversidad étnica y cultural de la Nación colombiana.

Las categorías del mestizaje, nombradas en los manuales escolares como mestizo, mulato, zambo y grupo triétnico, hacen parte de la clasificación social organizada con base en la idea de raza. Clasificación social impuesta por el eurocentrismo como intersubjetividad de las relaciones sociales racistas del patrón mundial de poder del capitalismo colonial y moderno (Quijano, 200o). La identificación categorial consiste en procesos y actividades situacionales y contextuales de identificarse a sí mismos y a los demás como miembros de una clase de personas que comparten algún principio categorial como raza, etnia o nación (Brubaker y Cooper, 2005). Así, las categorías de visión de lo social son resultado de la construcción social de unas clasificaciones realizadas mediante la selección de unos criterios (y la omisión de otros) para producir un conjunto de propiedades características de los miembros de un grupo que los incluya como tales y que excluya a otros. En este caso, la clasificación separa, por un lado, al grupo de los considerados más o menos puros racialmente: blancos, indios y negros, pertenecientes a las razas blanca, cobriza y negra. Por otro lado, al grupo de los mestizos, mulatos y zambos, considerados mezclas de los anteriores.

Las categorías sociales se ponen en escena y cobran sentido en las dinámicas sociales e históricas específicas, en las cuales se configuran determinadas relaciones de poder a nivel local, nacional e internacional. En este documento se sugiere que en los manuales escolares de geografía examinados, si bien el contenido sobre el mestizaje es escaso, se evidencia la ideología dominante con la cual se reproduce, justifica y legitima la hegemonía ejercida por los grupos de élite (Van Dijk, 2008); por consiguiente, la identificación de la población mediante las categorías del mestizaje hace parte, creemos, de la autocomprensión de las élites, entendida como subjetividad situada, la representación que tienen de sí mismas, de su ubicación en el espacio social y de su preparación para actuar (Brubaker y Cooper, 2005).

El mestizaje, en tanto ideología en la que se establece una identificación de la población basada en la idea de raza, enseñada en los contenidos de los manuales escolares, ha sido reportado por Herrera et al. (2003), quienes manifiestan que en los manuales escolares de ciencias sociales publicados en Colombia durante la primera mitad del siglo xx se acepta ser una mezcla de blancos con indios y negros, aunque se expresa la melancolía por querer ser blancos. Las miradas mestizas vergonzantes identifican en la misma lo malo que tenía el ser colombiano, los defectos de los ciudadanos y las posibles causas de la degeneración moral y social del pueblo. La educación y la cristianización les servían a las élites como estrategia para limpiar del ser colombiano lo que se tenía de negro, indígena y campesino, vía para acceder a la ciudadanía civilizada.

En Chile, Garrido (2007) examinó los textos escolares oficiales de educación básica para séptimo y octavo año, en la asignatura de Historia y Geografía, correspondientes al período 198I-1994. Manifiesta que el mestizaje se trata con una perspectiva racista, en que los mestizos, definidos como la mezcla entre los tipos raciales, se describen mediante la unión entre el fenotipo con las características culturales, desde un punto 
de vista según el cual la imagen del mestizo se construye como una instancia de blanqueo, por el reconocimiento a un mayor aporte de lo español, valorado como mejor y positivo, en oposición al legado de los indígenas, que sería escaso e inferior. En tal caso, el mestizaje se reconoce, aunque muchas veces se construye como instancia de no reconocimiento a lo indígena, ya que se identifica lo mestizo con lo malo del ser nacional o que se atribuye lo negativo del mestizo al indígena.

\section{Los progenitores: blancos, indios y negros}

El mestizaje en los manuales escolares de geografía de Colombia publicados entre 1975 y 1990 se aborda bajo el criterio del cruzamiento biológico entre las categorías raciales nombradas como blanco, indio y negro, aduciendo que la mezcla produce subtipos raciales denominados mestizo (entre blanco e indio), mulato (entre blanco y negro) y zambo (entre indio y negro); además se diferencia una categoría conocida como triétnico, que sería una mezcla equilibrada entre blanco, indio y negro. Ver Figura I.

Figura i. Categorías raciales del mestizaje

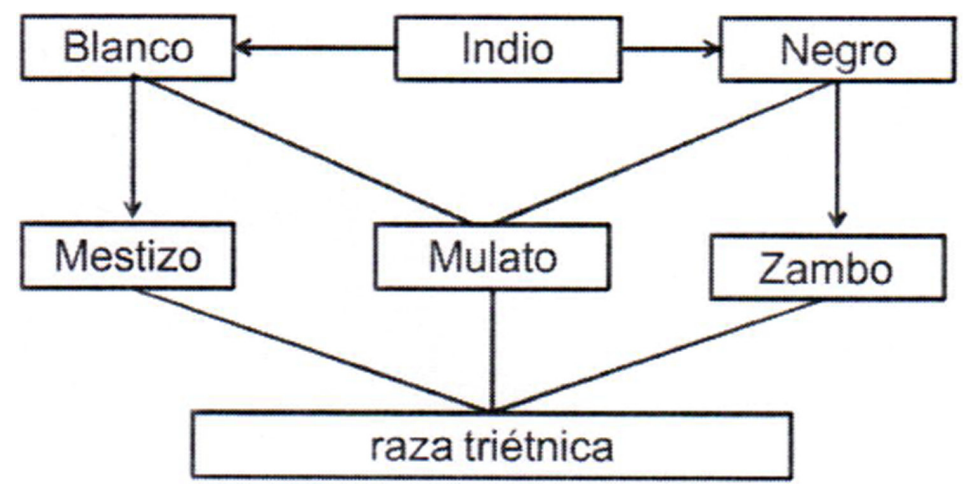

Fuente: Reelaboración a partir de contenido y gráfica de PARRA, 1976.

El cruce racial se presenta como un proceso natural: «El español vino sólo en un principio y se mezcló a las indias» (Sánchez, I981:97), y sin barreras sociales, así, Arbeláez (1975: 67) expresa que «Blancos, negros e indios conviven y se cruzan sin escrúpulo alguno y con gran indiferencia por esta mezcla nacional». Discurso similar al encontrado por Calzadilla y Salazar (2000) en el análisis de la percepción sobre la presencia del negro en Venezuela, en los libros de textos escolares de la Tercera Etapa de Educación Básica de Venezuela, en los cuales el mestizaje se enseña con imágenes benevolentes, como un proceso natural, sin violencia, propiciado por un europeo sin prejuicios raciales.

La idea de mestizaje se inscribe en la representación de nación según la cual la población tiene sus orígenes en blancos, indios y negros pertenecientes a las tres razas (blanca, cobriza y negra), también nombradas como grupos raciales, tipos humanos 
fundamentales de la población colombiana o grupos étnicos, cada una aportando al ser colombiano determinadas características biológicas, psíquicas, sociales y culturales. El modelo de configuración de la nación articula el racismo como recurso de clasificación jerárquica de la población, cuyo esquema parece tener como hilo conductor el grado de pureza biológica y el nivel de asimilación a la cultura de la categoría raza blanca, con la cual se identifican las élites. El léxico usado, con términos como aporte, legado y herencia, suaviza los conflictos, la explotación y la dominación de las relaciones sociales racistas. De ahí que el idioma español y la religión católica aparezcan como un legado de la raza blanca en vez de imposición cultural, o que el sometimiento y dominio de la gente categorizada como negro se muestre como un aporte biológico.

Se hace una jerarquización de los llamados aportes de las categorías raciales, de tal manera que aquellos provenientes de la categoría blanco son mejor valorados. En tal caso, se manifiesta que de la raza blanca o del español heredamos las instituciones sociales y administrativas, las costumbres, «[...] junto con los más importantes aportes culturales de la Europa Occidental, tales como el idioma español y la religión católica, entre muchos otros» (Marañón y otros, 1986: II7), en contraste con el legado de la cultura de las categorías heteroidentificadas como indio y negro, considerado como poco e inferior:

Podemos asegurar que la cultura colombiana es heredera de la tradición cristiana y occidental traída por los Españoles; poco nos queda de los Indios y el negro no pudo traer más cultura que algunos rudimentos folclóricos. Pero esa herencia cultural se hace más vigorosa en la religión, el Idioma y el folclor (Sánchez, I98I: III).

Los criterios biológicos remiten a ubicar el aporte de la categoría negro, expresando que consiste en su gran resistencia al clima tropical y su fortaleza física. En lo concerniente a los aportes de las cualidades psicológicas, hay tendencia a una mejor valoración de los rasgos de personalidad de la categoría blanco, entre los que se menciona la tenacidad, el regionalismo, el espíritu religioso, la belicosidad, la altivez, el orgullo y el sentido del honor. De los indígenas, se menciona una combinación de rasgos que pueden ser calificados tanto positivos como negativos: la laboriosidad, el espíritu pacífico, la resignación ante el dolor, la desconfianza, la hipocresía, la timidez, el gran valor, la belicosidad, la altivez y el espíritu guerrero, independiente y valiente. De la categoría negro, Sánchez (198r: 98) menciona que aportan la imaginación, la indolencia y la reserva ante las demás razas.

Dicha jerarquización de los aportes de cada categoría racial está en concordancia con el esquema clasificatorio manejado en los manuales escolares examinados, el cual sitúa a la categoría raza blanca como superior en contraste con las categorías indio y negro. En consecuencia, la categoría blanco se representa positivamente, se ubica en el clima templado de la región andina, se le otorga predominancia política en la construcción de la nación, se asocia con mayor actividad económica, el desarrollo cultural y la civilización, se aprecia la cultura de los conquistadores y colonizadores, centrada en el idioma español y la religión católica, se mencionan rasgos de personalidad en los que se acentúa la acción, el honor y la religiosidad. Mientras que la gente y la cultura de la población categorizada como indio y negro aparece con una representación negativa o subordinada, a través de atribuirle significados opuestos a la categoría blanco. A los pueblos indígenas se los clasifica jerárquicamente en andinos habitantes de las mesetas y montañas de los Andes, considerados con más desarrollo social y cultural; los caribes asociados a la Costa Atlántica, posicionados 
en una escala media, se les asigna cualidades relacionadas con la guerra y la ferocidad, y a la categoría indios de las tierras bajas, se los sitúa en la base de la escala social, se les percibe como salvajes, primitivos, pocos y dispersos. La categoría negro se relaciona con la esclavitud, con África, con las tierras bajas como las costas y las orillas de los ríos en los valles interandinos, con significados centrados en el cuerpo (fuerza física, resistencia al clima cálido, danza con mucho movimiento), con estereotipos como la imaginación y la alegría.

Es de anotarse que en el esquema clasificatorio de los manuales escolares de la época se pone de manifiesto el determinismo geográfico que vincula la geografía y el clima con el carácter de las poblaciones. En consecuencia, la zona intermedia de los Andes es considerada mejor para el asentamiento humano, con un clima frío y templado, así asimilado al de Europa. Continúa la Costa Atlántica, en una posición intermedia, con clima cálido seco. Finalmente, las tierras bajas de los Llanos Orientales y las selvas tropicales de la Amazonía y la Costa Pacífica, con clima cálido y húmedo, considerado poco propicio para la vida humana. En la siguiente cita, obsérvese que la población que habita en la zona intermedia de los Andes se representa positivamente (laboriosa, franca y religiosa), en comparación con la gente que vive en los páramos, menos valorada, con cualidades que se asignan a la categoría indio (reservado, melancólico, poco conversador, amante de las bebidas alcohólicas) y a la gente que vive en las tierras bajas, representada con los estereotipos que suelen atribuirse a la categoría negro (charlatán, expansivo, amante de la música caliente y el baile, menos laborioso):

En Colombia el temperamento del hombre varía de acuerdo con los distintos climas: los hombres de las montañas son laboriosos, francos y religiosos. El clima no es obstáculo para sus labores agrícolas como sí lo pueden ser en las tierras ardientes y esa es la razón por la cual en Colombia siempre se ha cultivado en la montaña y no en la llanura. El habitante de los páramos es reservado, más bien melancólico, poco conversador y su única expansión son las bebidas alcohólicas, principalmente la chicha cuando se trata de habitantes del oriente del país. [...]. El calentano, habitante de las tierras ardientes, es charlatán, expansivo, amante de la música caliente y el baile, pero menos laborioso (Parra, 1976: 105).

En resumen, el mestizaje en los manuales escolares de geografía examinados se expresa como resultado de un cruzamiento racial, en el cual cada categoría racial, blanco, indio y negro, aporta características particulares a la nación colombiana, siendo el legado de la raza blanca el mejor valorado en oposición a la gente heteroidentificada como indio y negro.

\section{La herencia}

En un primer momento, se da a entender que las categorías del mestizaje se basan en las características biológicas del cuerpo como principio categorizador, pues la definición inicial las presenta como resultado del cruce biológico entre las llamadas razas: blanco, negro e indio. Sin embargo, la descripción basada en criterios biológicos es poco frecuente. Algunos de los autores hablan de la sangre, así como de la proporción de sangre, en las categorías del mestizaje. En la siguiente cita, obsérvese que se toman en cuenta rasgos fenotípicos como el tipo de cabello y el color de la piel, si bien los colores son complicados de delimitar: 
De la presencia de los tres grupos étnicos resultan los tipos triétnicos cuyas características varían muy poco, pues el pelo sigue lacio en los mestizos y la tez oscurece un poco; en los mulatos persiste el cabello resortado o espiralado y la tez blanquea un tanto; en los zambos el cabello se alisa un poco pero la tez persiste casi negra (Arbeláez, 1975: 68).

Una revisión más detallada muestra que las categorías raciales del mestizaje se llenan de contenido mencionando los rasgos de personalidad y las características socioculturales, y la información más recurrente se dedica a proporcionar datos cuantitativos sobre la población en cada categoría racial y su distribución espacial en el país. En consecuencia, mestizo, mulato, zambo y grupo étnico no operan como una categoría simple, a la cual se le asocian cualidades biológicas, sino que remite a una categorización más compleja con la cual se establece una correspondencia con criterios de diferente índole, relacionados con cualidades psíquicas, culturales, sociales y geográficas, que suelen mostrarse como características intrínsecas a la categoría, y, por consiguiente, crean el efecto de aparecer como propiedades distintivas características de cada categoría del mestizaje. En la Tabla i, se presentan las principales características asignadas a las categorías del mestizaje.

TABla i. Características atribuidas a las categorías del mestizaje

\begin{tabular}{|c|c|c|c|}
\hline Criterios & Mestizo & Mulato & Zambo \\
\hline Fenotipo & $\begin{array}{l}\text { (I). El pelo sigue lacio y } \\
\text { la tez oscurece un poco; } \\
\text { (8) piel sonrosada (si pre- } \\
\text { domina el blanco) }\end{array}$ & $\begin{array}{l}\text { (I). Cabello resortado o } \\
\text { espiralado y la tez blan- } \\
\text { quea un tanto }\end{array}$ & $\begin{array}{l}\text { (I). El cabello se alisa un } \\
\text { poco pero la tez persiste } \\
\text { casi negra }\end{array}$ \\
\hline Rasgos de personalidad & $\begin{array}{l}\text { (7): reservado, cortés, es- } \\
\text { céptico, amor al trabajo, } \\
\text { actitud para profesiones } \\
\text { como abogado y política; } \\
\text { (8): malicioso, taciturno, } \\
\text { reservado (del chibcha), } \\
\text { vivaz, comunicativo (del } \\
\text { blanco); cortés y afable }\end{array}$ & $\begin{array}{l}\text { (7): Generosidad, ánimo } \\
\text { festivo, imaginación y } \\
\text { poco entusiasmo por el } \\
\text { trabajo }\end{array}$ & \\
\hline Cultura & $\begin{array}{l}\text { (3): importante por su } \\
\text { desarrollo cultural }\end{array}$ & & \\
\hline Demografía & $\begin{array}{l}(\mathrm{I}): 58 \%,(2): 33-58 \%,(4): \\
57 \%(3,5,7): 48 \%,(8) \\
\text { mayor porcentaje del país }\end{array}$ & $\begin{array}{l}(\mathrm{I}, 4): \mathrm{I} 4,(2): \mathrm{I} 7-30 \% \text { con } \\
\text { Zambos, }(3,5,7): 24 \%\end{array}$ & $\begin{array}{l}(\mathrm{I}, 4): 3 \%,(3): \text { son pocos, } \\
(5): \mathrm{r} \%\end{array}$ \\
\hline Geografía & $\begin{array}{l}\text { (I): cordilleras, grandes } \\
\text { centros poblados; (2): } \\
\text { cordilleras, ciudad y } \\
\text { campo; (3): todo el terri- } \\
\text { torio, sobre todo en el in- } \\
\text { terior del país; (6): todas } \\
\text { las regiones; (7) Boyacá, } \\
\text { Cundinamarca, Llanos } \\
\text { Orientales, Nariño }\end{array}$ & $\begin{array}{l}(\mathrm{I}, 2) \text { : a lo largo de las } \\
\text { costas y de grandes ríos } \\
\text { interandinos, }(3,4,7,8) \\
\text { costas, (6): Cordilleras y } \\
\text { valles interandinos }\end{array}$ & $\begin{array}{l}\text { (I, 6): Llanura del Pací- } \\
\text { fico, (4): en los pueblos } \\
\text { de interior de la costa }\end{array}$ \\
\hline
\end{tabular}

Fuente: (I) Arbeláez (1975), (2) hme (s. f.), (3) Marañón y otros (1986), (4) Parra (1976), (5) Rojas (i986), (6) Salguero y otros (1988), (7) Sánchez (I98I), (8) Valencia y Romero (1977). 
Los rasgos de personalidad se muestran como herencias de las categorías raciales, blanco, indio y negro, claramente delimitadas en el descendiente. Valencia y Romero (1977: 8I-82) describen al mestizo escindiendo la herencia de las categorías raciales (indio y blanco), tal como aparece en la siguiente cita:

El tipo cundino-boyacense. Habitante de Cundinamarca y Boyacá, prototipo del mestizo. Ha heredado las características del español y del indio. Se le considera como trabajador, malicioso, taciturno, reservado, cuando predomina la sangre chibcha; y vivaz, de piel sonrosada, comunicativo, si en él predomina la sangre blanca. El grupo es calificado como exponente de la cortesía y la afabilidad.

Demarcación que también se hace dependiendo de la clasificación del indígena ascendiente, ya que los rasgos de personalidad, que se les atribuye desde la época de la conquista, se heredarían según la categoría de indio. En este orden de ideas, los chibchas legarían cualidades diferentes a la de los caribes. Los primeros heredarían su laboriosidad, su espíritu pacífico, la desconfianza y la timidez, mientras que los segundos heredarían su gran valor, belicosidad y espíritu independiente (cfr. Salguero y otros, I988: 154; Marañón y otros, 1986: II6). Se presupone la existencia de diferentes grados de mestizaje. En el decir de Sánchez (198I: 98) haciendo referencia al mestizo: «Es la mezcla del indio con el blanco. Muy frecuente desde la época de la conquista, admite diferentes grados según la sangre que predomine».

El mestizaje cultural es poco mencionado pues se asume que la cultura nacional corresponde a la cultura de la categoría blanco, a la que se le otorga la preminencia. Se acepta el folclor como una mezcla de las categorías raciales, con predominio del blanco para dos de los autores de los manuales escolares. En todo caso, se trata como una característica cultural vinculada al pueblo, a diferencia de las élites. En la región andina, se asocia con los campesinos, como legado de los españoles con mezcla de lo indígena: «El Bambuco, [...], más armónicos y de cadencia más lentas, son aires traídos de España y mezclados con el elemento musical indígena y alegran las fiestas del campesino de los Andes» (Sánchez, i98r: in7). En las costas, se da prevalencia a la herencia de la cultura de la categoría heteroidentificada como negro:

En este proceso el fondo español ganó la primacía pero los otros dos le dieron sello distintivo como elementos secundarios que facilitan la identificación de las regiones [...]. En las dos primeras zonas [Costa Atlántica y Pacifica] predomina el aporte de la raza negra, especialmente en la música, danza, leyendas y mitos. Existe en Palenque (Bolívar) una agrupación negra que conserva su dialecto primitivo y algunos rituales. En las zonas de Antioquia y Caldas, el «Cauca grande» y el Alto Magdalena, centro y oriente andino, corresponde a la mentalidad mestiza (HME, 1979: 235).

En lo concerniente a características sociales, al mestizo se le vincula con mayor desarrollo económico y con roles relacionados al desempeño profesional y a la política. En los datos demográficos, se manifiesta que en el país habría poblaciones "puras» de blancos $(20 \%)$, negros ( $4-6 \%)$ e indios ( $\mathrm{I}-2 \%$ ), cuantificados en al menos un $25 \%$, mientras que las categorías productos del cruce biológico sumarían aproximadamente el $75 \%$, dentro de las cuales la mayoría serían mestizos (48-58\%) seguidos de mulatos (I4-24\%) y zambos. Los zambos poco se cuantifican o se hace como parte de los mulatos, aduciendo que se trata de un número reducido. 
En la distribución geográfica de las categorías del mestizaje, los mestizos se asocian con todo el país, especialmente a la región andina y a las ciudades. El grupo triétnico se relaciona con zonas de la región andina como Antioquía, Caldas, Santander y Valle del Cauca, si bien algunos autores también los sitúan en la Costa Atlántica. Los mulatos se vinculan con las costas Atlántica y Pacífica y con los valles interandinos. Los zambos, cuando se mencionan, son ubicados en las costas, en especial la Costa Pacífica.

El grupo triétnico se usa para identificar a la población que se supone que tiene una mezcla en proporciones equilibradas de blanco, indio y negro, proveniente del mestizaje entre mestizos, zambos y mulatos: «Con el correr de los años, durante la colonia y la era republicana, mestizos, zambos y mulatos se han mezclado, produciendo nuevos mestizajes que en términos generales han dado un tipo humano ya familiar en todos los rincones del país y que conocemos con el nombre ya citado de triétnico» (Parra, 1976: 83). En consecuencia, el predominio de la «raza trietnica» le daría a Colombia una particularidad y unidad racial conformando un nuevo grupo étnico, constituido por un ser humano ideal no sólo para el país, sino también para Latinoamérica, así como para el dominio del trópico:

El triétnico. Como su nombre lo indica posee sangre de los tres grupos básicos: indio, blanco y negro, en proporciones más o menos iguales; hoy se afirma que este sería el tipo humano ideal para el desarrollo cultural latinoamericano [...]. Las mezclas de los grupos anotados han originado: el mestizo (blanco-indio), grupo racial más importante del país; el mulato (blanco-negro); zambo (indio-negro); y el triétnico (blanco-indionegro). Cada grupo racial, blanco, negro e indio han aportado sus características propias, físicas y espirituales al hombre colombiano, para hacer de él, un elemento étnico diferente (Marañón, et al., 1984: II5-I32).

En síntesis, el esquema clasificatorio en el que está integrada la ideología del mestizaje racial organiza, además de los rasgos biológicos como criterio de categorización, la correspondencia con características psíquicas, sociales, culturales y geográficas, articuladas de una forma que el mestizaje no se entiende como una combinación para generar un individuo o una población nueva, sino que los descendiente del cruce racial se presentan como portadores de cualidades separadas y distinguibles de las llamadas herencias de sus ascendientes, dando continuidad al manejo del esquema como una herramienta para la identificación de la población desde la perspectiva del racismo.

\section{Los herederos: mestizos/mulatos/zambos}

Las categorías raciales del mestizaje se jerarquizan siguiendo el orden: mestizos/ mulatos/zambos. En la siguiente cita se observa que al mestizo se le sitúa en una posición más alta, mediante el uso del adjetivo «más importante», seguido del mulato en una ubicación intermedia, mientras que a los zambos se los relega a la base:

El mestizo. Es el resultado de la unión del blanco con el indio; actualmente es el grupo racial más importante del país, no sólo por el número de sus representantes, que es el mayor entre todos, sino también por su desarrollo cultural; está distribuido indistintamente a través del territorio, pero sobre todo en el interior del país. El mulato. 
Resulta del cruce entre el blanco y el negro; le sigue en importancia al anterior y se localiza especialmente en nuestras costas. El zambo. Mezcla del indio con el negro; sus representantes son pocos en la actualidad y serán cada vez menos en el futuro (Marañón et al., 1984: II4-II5).

En la cita anterior y en la que sigue se hace una mejor representación del mestizo al ubicarlo en la zona andina, atribuirle mayor desarrollo cultural, más cantidad de población, así como rasgos de personalidad valorados positivamente, entre ellos, la cortesía, la afabilidad, la reserva, el amor al trabajo y aptitud en las áreas profesionales y la política. La posición intermedia del mulato se marca con una cantidad media de población (entre mestizos y zambos), se le sitúa en las costas, preferentemente en la Costa Atlántica (entre los Andes y las selvas tropicales) y los valles interandinos (más abajo de la sabana cundiboyacense), se le señalan cualidades de fiestero, generoso, imaginativo y poco esforzado en el trabajo, estereotipos similares a los que se le adjudican a la categoría nombrada como negro. El zambo es posicionado en la base de la escala del mestizaje; se le localiza en tierras bajas como valles interandinos y las costas, en especial, la Costa Pacífica; su número se considera reducido, no se contabiliza o se le otorga una cantidad baja, entre I y $3 \%$, que se augura, disminuirá en el futuro, se considera producto de una mezcla simbólicamente ligada con lo prohibido y anormal, atribuida al rechazo entre los grupos sociales: «Resultantes de la unión de negros con los indios. Aunque fue muy limitada, pues los dos grupos, por temperamento y quizá por sus creencias, se rechazaban» (Valencia y Romero, 1977: 80-8I) y al tabú:

[...]. El mestizo se caracteriza por la reserva y cortesía, escepticismo, amor al trabajo, aptitud para profesiones tales como la abogacía o la política. Este tipo racial predomina en las regiones orientales de Boyacá, Cundinamarca y Llanos Orientales y en el Sur, especialmente en Nariño. Es el grupo étnico más importante del país. El mulato. Es el resultado de la mezcla del blanco con el negro. Aunque menos frecuente que el mestizo, es sin embargo elemento predominante en las costas; se caracteriza por su generosidad, ánimo festivo, imaginación, y poco entusiasmo por el trabajo. El zaмвo. Es la mezcla del negro con el indio. Es un grupo poco numeroso, pues estas dos razas se repelen, hasta el punto de que en algunas tribus indígenas el mezclarse con negro es tabú (delito) (Sánchez, 1981: 98-99).

La categoría catalogada como triétnico se menciona positivamente; sin embargo, poco se alude a su definición. Se le ubica en la zona andina, especialmente en determinadas regiones: «Hacia este ideal de mezcla se acercan algunos grupos regionales tales como el antioqueño-caldense; el santandereano de la región del Lebrija y algunos sectores del Valle del Cauca» (Sánchez, I98I: I00), algunos autores le sitúan en la Costa Atlántica. Por la ubicación geográfica, al parecer, la categoría se concibe como parte de la subclasificación que se hace al interior de la zona andina, en la cual, la población de la sabana cundiboyacense es la mejor valorada. En tal caso, esta categoría queda ubicada en una posición subordinada a la categoría blanco.

La jerarquización mestizos/mulatos/zambos está organizada en función de la primacía dada a la categoría raza blanca. El mestizo es mejor valorado cuando se supone que tiene mayor proporción del blanco, y las características representadas positivamente en el mestizo se atribuyen al blanco. El llamado aporte de lo indígena depende de la clasificación que se hace de la gente que vivía al momento de la llegada 
de los europeos, se menciona el mestizaje con los chibchas, grupo mejor valorado entre los indígenas, en especial si es muisca, seguido del mestizaje con los caribes, en una posición intermedia. En cambio, no se hace referencia al aporte y al mestizaje con los grupos habitantes en tierras bajas, a quienes se les asignan las características más negativas del esquema clasificatorio. En tal caso, el mestizo de la zona cundiboyacense es mejor valorado al de otras regiones, ya que la población de esta subregión se «caracteriza por el gran mestizaje hispano-chibcha» (Rojas, I986, II5). El mulato se asocia con aportes más relacionados con la categoría negro, omitiendo referencias a la herencia de la categoría blanco. El zambo es una categoría indefinida a partir de las características de sus ascendientes, simplemente se le instituye como una identidad negativa.

Al parecer, la identificación de la población mediante las categorías del mestizaje hace parte de la clasificación social más global basada en la idea de raza, desde la autocomprensión de las élites, entendida como subjetividad situada (Brubaker y Cooper, 2005), tal como se evidencia en la Figura 2, del manual de los Hermanos Maristas (s. f.):

Figura 2. Categorías raciales del mestizaje en el espacio social

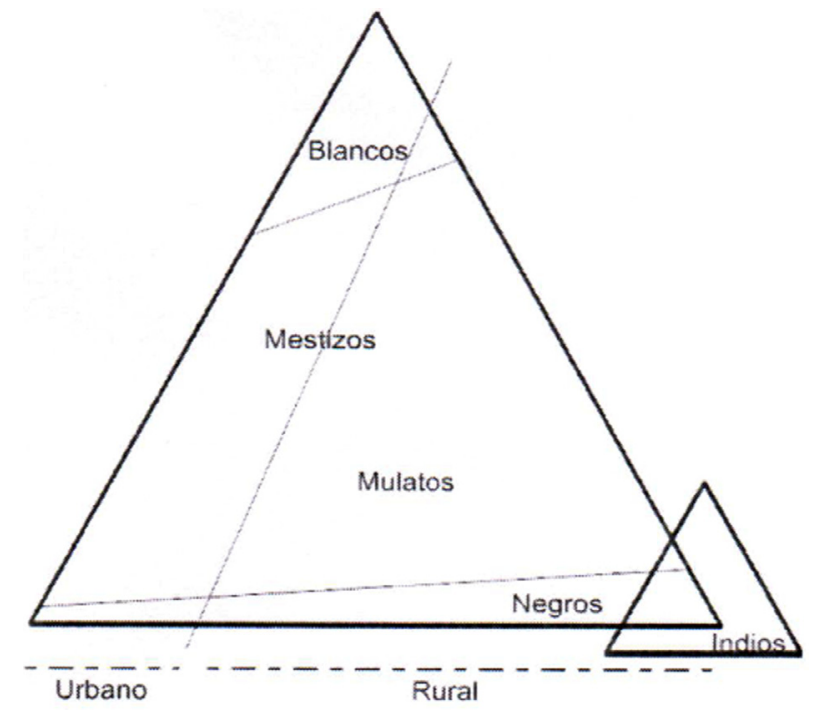

Fuente: Hermanos Maristas, s. f.

En esta gráfica el esquema clasificatorio integra las categorías raciales (blanco, indio, negro) con las categorías del mestizaje (mestizo, mulato) y la oposición entre la ciudad y lo rural; siendo la vida urbana mejor valorada y asociada con la categoría blanco, así, Arbeláez (1975: 8I) expresa que: «como producto de la aglomeración de las habitaciones humanas existe más que todo como efecto de la civilización entre los blancos». Las élites se posicionan en la cúspide de la pirámide social, se perciben como racialmente blancas «El grupo blanco prefiere vivir en los centros urbanos y en especial en la capital y ciudades de la región andina» (HME, s. f.: 229), algunas de 
ellas habitando la zona rural. Continúan las categorías definidas a partir de la mezcla con la raza blanca. Los mestizos, localizados preferentemente en la región andina, en las ciudades y en el campo; «[...]. Aunque la población mestiza predominaba en las zonas rurales su número aumenta en las ciudades porque hay una inmigración muy grande de los campos a las ciudades» (Hermanos Maristas [HME], s. f.: 229). Sigue la categoría mulatos, a la que geográficamente se vincula más con la zona rural, las Costas Atlántica y Pacífica y los Valles interandinos. En la base de la pirámide se confina a la categoría heteroidentificada como negro, habitando la mayoría en el campo, unos pocos en la ciudad, en las Costas, en especial en las tierras bajas de la Costa Pacífica y a las orillas de los ríos interandinos. La categoría indio se presentan como una sociedad aparte, ubicada en la parte inferior, asociada con las tierras bajas del Pacífico, Amazonia y los Llanos Orientales, la Guajira y en algunos lugares de los Andes como la Sierra Nevada de Santa Marta, Sierra de los Motilones y Tierradentro.

En el esquema de clasificación, la categoría mestizo sirve de referencia para hacer la distinción de las élites con respecto al resto de la población urbana y campesina, en especial, de la zona andina. La clasificación jerárquica de la población en este caso enlaza el racismo con criterios vinculados con la clase social, la dicotomía urbano/rural y la ideología del desarrollo. Las élites se representan a sí mismas como católicas, urbanas, hablando el español estándar, habitando en la zona intermedia de los Andes, distintas por «[...] el abolengo, la riqueza y en otros aspectos secundarios como educación, refinamiento en los modales, distinción intelectual, círculo de amistades y estilo de vestir» (HME, s. f.: 237). El resto de la población estaría constituida por mestizos, con una representación diferenciada por Rojas (I986: II5) de los citadinos (suele ser formal, locuaz y cortés, pero tremendamente reservado y de opiniones algo subjetivas), en comparación con los campesinos y habitantes pobres de la ciudad (tímidos, desconfiados, actitudes que han recibido influencia de la conquista española sobre los indígenas), quienes hablarían un español con variación ya que «Actualmente hay uniformidad en el lenguaje hablado entre las gentes cultas de todo el país, $[\ldots .$. . Las mayores variaciones se hallan en las zonas rurales» (HME, s. f.: 233). Los mestizos y mulatos vendrían a constituir una buena proporción de la gente categorizada como el pueblo o los pobres, a la que se le asocia con tener muchos hijos, el folclor, el trabajo manual, la resistencia al cambio, la superstición, la escasa instrucción, la ignorancia, los malos hábitos alimenticios, el alcohol y los problemas del subdesarrollo (la pobreza, explosión demográfica, las enfermedades, la malnutrición, la carencia de servicios públicos, la insuficiencia y la precariedad de la vivienda).

\section{Conclusión}

Se sugiere que en los contenidos de enseñanza sobre el mestizaje, en manuales escolares de geografía de Colombia publicados entre 1975 y 1990, subyace un discurso ideológico que expresa la subjetividad de las élites del momento, la representación que tienen de sí mismas y del resto de la población, bajo el lente del racismo. Las categorías del mestizaje hacen parte de la clasificación jerárquica de la población organizada con base en la idea de raza que da predominio a la categoría blanco con la cual se autodefinen las élites, quienes se autocomprenden como seres humanos 
mejores y superiores que el resto de la gente, categorizada como mestizo, mulato, zambo, indio, negro y el pueblo. Mestizo, mulato y zambo se definen mediante la correspondencia de la categoría racial del mestizaje con cualidades culturales, sociales, psíquicas y geográficas que suelen aparecer como características inherentes a cada categoría, y que se manejan como herramientas para subordinar y excluir a los otros grupos sociales.

\section{Bibliografía}

Brubaker, Rogers y Cooper, Frederick (2005) Más allá de la «identidad». En W. Loic (dir.) Repensar los Estados Unidos para una sociología del hiperpoder. Barcelona: Anthropos.

Calzadilla, Pedro y Salazar, Zalena (2000) El negro la presencia ausente. Negro y esclavitud, imágenes en los textos escolares. Revista de Teoría y Didáctica de las Ciencias Sociales, n. ${ }^{\circ}$. Caracas.

Choppin, Alain (2000) Pasado y presente de los textos escolares. En J. Ruiz, La cultura escolar de Europa. Tendencias históricas emergentes. Madrid: Biblioteca Nueva.

Garrido, Carlos (2007) Visiones racistas en los textos escolares de Historia de $7 .^{\circ}$ y $8 .^{\circ}$ básico, en Chile (i98I-I994). En Ministerio de Educación de Chile, Primer Seminario Internacional de Textos Escolares. Santiago de Chile.

Herrera, Martha; Pinilla, Alexis y Suaza, Luz (2003) La identidad nacional en los textos escolares de ciencias sociales. Colombia 1900-1950. Bogotá: Universidad Pedagógica Nacional.

Quijano, Aníbal (2000) Colonialidad y Clasificación Social. Journal of World Systems Research, n. ${ }^{\circ} 6$ (2). Special Issue. Festschrift For Immanuel Wallerstein - Part I.

VAn Dijк, Teun (2008) Ideología y discurso. Barcelona: Ariel.

\section{Manuales escolares como fuente de información}

Arbeláez, Federico (1975) Geografía Física, General y de Colombia, i. Bogotá: Norma.

hme. Hermanos Maristas (s. f.) Geografía Física y Humana Aplicada a Colombia, primer año de bachillerato, Cali, Norma.

Marañón, Mórtiner; Gómez, Hilda; Vega, Alcira; López, Gilma y Prada, Cora (1984-1986) Geografía Física, General y de Colombia i. Bogotá: Norma.

PARrA, Juan (1976) Geografía física aplicada a Colombia y Latinoamérica. Medellín: Susaeta Ediciones.

Rojas, Ruth (1986-1989) Brújula Geografía de Colombia, 6. Bogotá: Voluntad.

Salguero, Jorge; Rodríguez, Rosalbina; Rojas, Inés y Gómez, Carlos (1988) Espacio y Sociedad Geografía General y de Colombia. Bogotá: Norma.

Sánchez, Hernando (1981) Geografía Física General y de Colombia. Medellín: Bedout.

Valencia, Pedro y Romero, Argenis (1977) Geografía general - física y de Colombia, i. Bogotá: Ediciones Cultural, segunda edición. 